\title{
COMPRESSIVE STRENGTH AND SURFACE ROUGHNESS OF CERAMIC REINFORCED GLASS IONOMER SUBJECTED TO CHEMICAL CHALLENGE
}

\author{
Randa M. Hafez*, Maha E.Elkorashy** and Mayada S. Sultan ${ }^{* * *}$
}

\begin{abstract}
Objective: This research was conducted to investigate the effect of chemical challenge on the compressive strength (CS) and surface roughness (Ra) of a ceramic reinforced glass ionomer in comparison to a nanofilled resin composite.
\end{abstract}

Methods: A total of 60 disc specimens (6mm height $\mathrm{x} 4 \mathrm{~mm}$ diameter) were prepared for the compressive strength testing and another 60 disc specimens (5mm diameter x $2 \mathrm{~mm}$ thickness) for the surface roughness testing. Specimens were divided into 2 groups $(n=30)$ according to the material used; ceramic reinforced glass ionomer (Amalgomer CR, Advanced Health Care Ltd, Tonbridge, Kent, UK) and nanofilled resin composite (Filtek ${ }^{\mathrm{TM}}$ Z350 XT, 3M ESPE, St.Paul, MN,USA). Each group was divided into 3 subgroups $(n=10)$ according to the storage media; distilled water (control), $0.02 \mathrm{~N}$ citric acid and $50 \%$ ethanol. Specimens were stored for 7 days at $37^{\circ} \mathrm{C}$. After storage period, they were subjected to compressive loading using a universal testing machine and surface roughness testing using white light interferometer. Data were tabulated and statistically analyzed using Two-way ANOVA followed by Bonferroni's post-hoc test.

Results: Amalgomer CR recorded a significantly lower CS and higher Ra than nanofilled resin composite under different storage media. Citric acid revealed the lowest CS of Amalgomer CR followed by ethanol in comparison to distilled water with significant difference between them. For nanofilled resin composite, both citric acid and ethanol significantly decreased CS. Ethanol showed the highest $\mathrm{Ra}$ values for both restorative materials.

Conclusions: The performance of Amalgomer CR under different storage media was inferior to nanofilled resin composite regarding compressive strength and surface roughness. Citric acid severely affected compressive strength of Amalgomer CR. Nanofilled resin composite was able to preserve its surface roughness within the clinically acceptable threshold after chemical challenge in contrary to Amalgomer CR.

KEY WORDS: ceramic reinforced glass ionomer, citric acid, ethanol, compressive strength, surface roughness.

\footnotetext{
* Professor, Conservative Dentistry Department, Faculty of Oral and Dental Medicine, Cairo University

** Lecturer, Operative Dentistry Department, Faculty of Dentistry, Fayoum University

*** Lecturer, Operative Dentistry Department, Faculty of Dentistry, Assiut University
} 


\section{INTRODUCTION}

Glass ionomer cements (GICs) are one of the most attractive restorative materials. They are characterized by interesting properties as chemical bonding ability, high biocompatibility, anticariogenic property due to fluoride release and coefficient of thermal expansion and contraction matching to that of the tooth structure ${ }^{1,2}$. On the other hand, they suffer from poor mechanical properties as low fracture strength, toughness and wear resistance which limits their use in stress bearing areas ${ }^{3}$. Based on the poor mechanical properties of glass ionomer cements, numerous attempts have been done in order to improve their strength properties ${ }^{2,4-6}$.

Amalgomer ${ }^{\mathrm{TM}} \mathrm{CR}$ is a recent ceramic reinforced posterior restorative glass ionomer where zirconia fillers were incorporated to achieve strength properties comparable to that of amalgam. As stated by the manufacturer, it has low wear rates and excellent resistance to fracture and cracking 7 .

Nanofilled resin composite is considered one of the most commonly used restoratives nowadays. It fulfills the clinical requirements as a posterior restoration in terms of high strength properties and high resistance to abrasion. This is achieved via the incorporation of filler particles in the nanoscale which allow high filler loading ${ }^{8}$.

Mechanical properties describe the behavior of the material under functional loading ${ }^{9}$. During clinical service, restorations are subjected to combination of forces resulting in development of different types of stresses as compressive, tensile and shear stresses ${ }^{10}$. Compressive strength testing is one of the most commonly employed testing methods for evaluation of the strength properties of dental restoratives ${ }^{9-11}$.

The surface texture of tooth-colored restorative materials plays an important role in their clinical performance. Restorations with surfaces irregularities facilitate colonization of bacteria and biofilm maturation with increasing risk of development of dental caries and periodontal diseases ${ }^{12}$.

In the oral environment, exposure of dental restoratives to saliva, food components and beverages can degrade and age dental restorations. It was reported previously that resin matrices of dental composites become softened with exposure to organic acids and various constituents of food and drinks ${ }^{13}$. Also, glass ionomer cements showed leaching out of inorganic components with great susceptibility to hydrolytic degradation at the matrix/filler interface under different environmental conditions ${ }^{14}$. Therefore, the chemical environment in the oral cavity might have a critical influence on the properties of dental restoratives and subsequently their clinical performance.

Hence, evaluation of the compressive strength and surface roughness of a ceramic reinforced posterior restorative glass ionomer under chemical challenge of the oral environment in comparison to a nanofilled resin composite might be of value.

\section{MATERIALS AND METHODS}

Two tooth colored restorative materials were used in the current study; ceramic reinforced glass ionomer (Amalgomer ${ }^{\mathrm{TM}} \mathrm{CR}$ Posterior Restorative glass ionomer) and a nanofilled resin composite (Filtek ${ }^{\mathrm{TM}}$ Z350 XT Universal Restorative) as shown in (table 1). Three storage media; distilled water (control), $0.02 \mathrm{~N}$ citric acid and 50\% ethanol were also used in the study.

\section{Specimens' preparation and grouping}

A total of 120 specimens were prepared for the present study. Sixty cylindrical specimens were prepared for the compressive strength test, $6 \mathrm{~mm}$ in height $\mathrm{x} 4 \mathrm{~mm}$ in diameter, and 60 disc specimens for surface roughness testing, $5 \mathrm{~mm}$ in diameter x $2 \mathrm{~mm}$ in height. Specimens for each test were prepared using a specially designed split teflon 
TABLE (1) The materials used in the study

\begin{tabular}{|c|c|c|c|c|}
\hline \multirow{2}{*}{ Product } & \multirow{2}{*}{ Description } & \multicolumn{2}{|r|}{ Composition } & \multirow{2}{*}{ Manufacturer } \\
\hline & & Matrix & Fillers & \\
\hline Amalgomer ${ }^{\mathrm{TM}} \mathrm{CR}$ & $\begin{array}{l}\text { Ceramic } \\
\text { reinforced } \\
\text { GIC }\end{array}$ & $\begin{array}{l}70-80 \% \text { Glass powder } \\
10-20 \% \text { Acrylic acid } \\
\text { polymer }\end{array}$ & - Zirconia fillers & $\begin{array}{c}\text { Advanced Health } \\
\text { Care Ltd, Tonbridge, } \\
\text { Kent, UK }\end{array}$ \\
\hline $\begin{array}{c}\text { Filtek }^{\mathrm{TM}} \mathrm{Z} 350 \mathrm{XT} \\
\text { Universal Restorative } \\
\text { material }\end{array}$ & $\begin{array}{l}\text { Nanofilled } \\
\text { resin } \\
\text { composite }\end{array}$ & $\begin{array}{l}\text { Bis-GMA } \\
\text { UDMA } \\
\text { TEGDMA } \\
\text { PEGDMA } \\
\text { Bis-EMA }\end{array}$ & $\begin{array}{l}\text { - Non- agglomerated } 20 \mathrm{~nm} \text { silica filler. } \\
\text { - Non-agglomerated } 4-11 \mathrm{~nm} \text { zirconia filler. } \\
\text { - Aggregated zirconia/silica cluster } \\
\text { filler } 0.6-10 \mu \mathrm{m} . \\
-72.5 \mathrm{wt} \%(55.6 \mathrm{~V} \%)\end{array}$ & $\begin{array}{l}\text { 3M ESPE, St.Paul, } \\
\text { MN,USA }\end{array}$ \\
\hline $\begin{array}{l}\text { Bis-GMA: Bisphenol } \\
\text { Bis-EMA: Bisphenol- } \\
\text { UDMA: Urethane dim } \\
\text { TEGDMA: Triethylen } \\
\text { PEGDMA: poly(ethyl }\end{array}$ & $\begin{array}{l}\text { diglycidylme } \\
\text { polyethylene } \\
\text { thacrylate } \\
\text { glycol dimetl } \\
\text { ne glycol) din }\end{array}$ & $\begin{array}{l}\text { hacrylate } \\
\text { slycol dietherdimethac } \\
\text { acrylate } \\
\text { ethacrylate }\end{array}$ & & \\
\hline
\end{tabular}

mold. The samples were divided into 2 groups $(n=30)$ according to the type of restorative material used; Amalgomer ${ }^{\mathrm{TM}} \mathrm{CR}$ conventional glass ionomer and Filtek Z350 XT Universal Restorative. Each group was further divided into 3 subgroups $(n=10)$ according to the storage medium; distilled water (control), $0.02 \mathrm{~N}$ citric acid and 50\% ethanol.

For specimens' preparation, a glass slide covered with a mylar strip (Stripmat, POLYDENTIA, CH-6805 Mezzovico, Switzerland) was used. For Amalgomer ${ }^{\mathrm{TM}} \mathrm{CR}$ specimens' preparation, the powder and the liquid (distilled water) were proportioned according to the manufacturer' instructions and mixed until a homogenous mix was obtained. The mix was then packed into the intended mold in one increment, covered with another mylar strip and a glass slide then pressed for $10 \mathrm{sec}$ to extrude the excess material and achieve a uniform smooth surface. The mix was left in the mold till complete setting. The specimens were then coated with a light cure glaze (AHfil LCG, Advanced Health Care Ltd, Tonbridge, Kent, UK) as recommended by the manufacturer and light cured for $10 \mathrm{sec}$ using LED light curing unit with an intensity of $1200 \mathrm{~mW} / \mathrm{cm}^{2}$ (Elipar ${ }^{\mathrm{TM}} \mathrm{S} 10,3 \mathrm{M}$ ESPE, St. Paul, USA). Regarding the resin composite specimens, they were prepared in the same manner as mentioned before and light cured for $40 \mathrm{sec}$ from top surface and $40 \mathrm{sec}$ from bottom surface. All specimens were prepared by the same operator.

Specimens were stored for $24 \mathrm{~h}$ at $37^{\circ} \mathrm{C}$ in distilled water to ensure complete setting. They were then immersed in one of the three storage solutions; distilled water (control), $0.02 \mathrm{~N}$ citric acid or $50 \%$ ethanol/water solution in labeled containers for 7 days at $37^{\circ} \mathrm{C}$ in an incubator ${ }^{15}$.

\section{Compressive strength testing}

After the storage period, specimens were subjected to compressive loading using a universal testing machine (Lloyd LR 5K, Lloyd Instruments Ltd, Hampshire, UK) operating using Nexygen software version 4.6. The load was applied along the long axis of the specimens with a load cell $5 \mathrm{KN}$ at a cross head speed $0.5 \mathrm{~mm} / \mathrm{min}$. The maximum load at fracture was recorded and the compressive strength was calculated in MPa by dividing the load with the cross sectional area of the specimen. 


\section{Surface roughness testing}

Surface roughness was measured using a white light interferometer. This was carried out using ZYGO Maxim-GP 200 profilometer, which is a general purpose surface optical profiler that measures the microstructure and topography of surfaces in three dimensions. Computerized phase stepping interferometry (PSI) upgraded with scanning white light interferometry (SWLI) and advanced surface texture software which analyzes areas as well as profiles and step height. A white light from a Halogen lamp incident on an interference filter with Full Width at Half Maximum $($ FWHM $) \approx 3-15 \mathrm{~nm}$ was used depending on the measuring technique. Three readings were recorded for each sample (2 readings from the peripheries and 1 reading form the center) and an average reading was calculated to represent the surface roughness for each specimen in $\mu \mathrm{m}$.

\section{Scanning Electron Microscopic Observation}

Two representative samples from each subgroup were evaluated by an environmental scanning electron microscope (Quanta FEG 250, FEI Company, Netherland). The surfaces to be evaluated were mounted on metallic stubs and assessed by SEM at magnification $1500 \mathrm{X}$ to scan surface topography.

\section{Statistical Analysis}

Numerical data were explored for normality by checking the data distribution using KolmogorovSmirnov and Shapiro-Wilk tests. All data showed normal distribution. Data were represented by mean, standard deviation (SD), range and 95\% Confidence Interval $(95 \% \mathrm{CI})$ values. Two-way ANOVA test was used to study the effect of material, storage media and their interactions on compressive strength (CS) and surface roughness (Ra). Bonferroni's posthoc test was used for pair-wise comparisons when ANOVA test revealed significance. The significance level was set at $\mathrm{P} \leq 0.05$. Statistical analysis was performed with IBM ${ }^{\circledR}$ SPSS $^{\circledR}$ Statistics Version 20 for Windows.

\section{RESULTS}

\section{Compressive Strength Results}

Two-way ANOVA test showed that material, storage media and their interaction had a statistically significant effect on mean compressive strength (table 2). Descriptive statistics of compressive strength were presented by mean, standard deviation (SD), minimum, maximum and 95\% confidence interval (95\% CI) values in Table (3).

TABLE (2) Two-way ANOVA results for the effect of material, storage media and their interaction on mean compressive strength (CS) in $\mathrm{MPa}$

\begin{tabular}{lccccc}
\hline \multirow{2}{*}{ Source of variation } & $\begin{array}{c}\text { Sum of } \\
\text { Squares }\end{array}$ & df & $\begin{array}{c}\text { Mean } \\
\text { Square }\end{array}$ & $\begin{array}{c}F- \\
\text { value }\end{array}$ & P-value \\
\hline Material & 231193.5 & 1 & 231193.5 & 3289.6 & $<0.001^{*}$ \\
Storage medium & 39188.6 & 2 & 19594.3 & 278.8 & $<0.001^{*}$ \\
Material x Storage & 14666.7 & 2 & 7333.3 & 104.3 & $<0.001^{*}$ \\
medium interaction & & & & & \\
\hline
\end{tabular}

$d f:$ degrees of freedom $=(n-1), *$ : Significant at $P \leq 0.05$

TABLE (3) Descriptive statistics of compressive strength (CS) values in $\mathrm{MPa}$

\begin{tabular}{|c|c|c|c|c|c|c|c|}
\hline \multirow{2}{*}{ 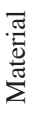 } & \multirow{2}{*}{$\begin{array}{l}\text { Storage } \\
\text { medium }\end{array}$} & \multirow[b]{2}{*}{ Mean } & \multirow[b]{2}{*}{ SD } & \multirow[b]{2}{*}{ Minimum } & \multirow[b]{2}{*}{ Maximum } & \multicolumn{2}{|c|}{$95 \% \mathrm{CI}$} \\
\hline & & & & & & $\begin{array}{l}\text { Lower } \\
\text { bound }\end{array}$ & $\begin{array}{l}\text { Upper } \\
\text { bound }\end{array}$ \\
\hline \multirow{3}{*}{ 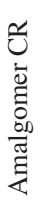 } & $\begin{array}{c}\text { Distilled } \\
\text { water }\end{array}$ & 148.8 & 6.0 & 140.4 & 156.9 & 142.5 & 155.1 \\
\hline & $\begin{array}{c}\text { Citric } \\
\text { acid }\end{array}$ & 30.3 & 4.4 & 24.6 & 37.2 & 25.7 & 35.0 \\
\hline & Ethanol & 116.3 & 8.3 & 105.6 & 128.9 & 107.6 & 125.0 \\
\hline \multirow{3}{*}{ 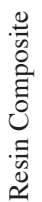 } & $\begin{array}{c}\text { Distilled } \\
\text { water }\end{array}$ & 289.9 & 5.5 & 280.8 & 295.4 & 284.1 & 295.7 \\
\hline & $\begin{array}{c}\text { Citric } \\
\text { acid }\end{array}$ & 246.7 & 12.1 & 230.8 & 262.7 & 234.1 & 259.4 \\
\hline & Ethanol & 239.6 & 11.0 & 226.0 & 257.7 & 228.0 & 251.1 \\
\hline
\end{tabular}

Bonferroni's post-hoc test (table 4) showed that Amalgomer CR revealed lower compressive strength with all storage media in comparison to resin composite. Regarding the effect of the 
storage media, Amalgomer CR showed the lowest compressive strength results with citric acid followed by ethanol then distilled water with statistically significant difference between them. For resin composite, both citric acid and ethanol showed significantly lower compressive strength in comparison to distilled water with no significant difference between them.

TABLE (4) Mean, standard deviation (SD) values and P-value of the effect of material and storage media on compressive strength (CS) in $\mathrm{MPa}$

\begin{tabular}{lccccc}
\hline \multirow{2}{*}{$\begin{array}{c}\text { Storage } \\
\text { medium }\end{array}$} & \multicolumn{2}{c}{ Amalgomer CR } & \multicolumn{2}{c}{ Resin Composite } & \multirow{2}{*}{ P-value } \\
\cline { 2 - 5 } & Mean & SD & Mean & SD & \\
\hline Distilled water & $148.8^{\mathrm{A}}$ & 6.0 & $289.9^{\mathrm{A}}$ & 5.5 & $<0.001^{*}$ \\
Citric acid & $30.3^{\mathrm{C}}$ & 4.4 & $246.7^{\mathrm{B}}$ & 12.1 & $<0.001^{*}$ \\
Ethanol & $116.3^{\mathrm{B}}$ & 8.3 & $239.6^{\mathrm{B}}$ & 11.0 & $<0.001^{*}$ \\
$P$-value & $<0.001^{*}$ & $<0.001^{*}$ & \\
\hline
\end{tabular}

*: Significant at $P \leq 0.05$, Different superscripts in the same column are statistically significantly different

\section{Surface Roughness Results}

According to Two-way ANOVA test, results showed that material and storage media had a statistically significant effect on mean Ra. The interaction between the two variables had no statistically significant effect on mean Ra (table $5)$. Descriptive statistics of surface roughness $(\mathrm{Ra})$ values in $\mu \mathrm{m}$ are presented in Table (6).

TABLE (5) Two-way ANOVA results for the effect of material, storage media and their interaction on mean surface roughness (Ra) in $\mu \mathrm{m}$

\begin{tabular}{lccccc}
\hline Source of variation & $\begin{array}{c}\text { Sum of } \\
\text { Squares }\end{array}$ & df & $\begin{array}{c}\text { Mean } \\
\text { Square }\end{array}$ & $F$-value & $P$-value \\
\hline Material & 0.148 & 1 & 0.148 & 133.4 & $<0.001^{*}$ \\
$\begin{array}{l}\text { Storage medium } \\
\text { Material x Storage }\end{array}$ & 0.070 & 2 & 0.035 & 31.7 & $<0.001^{*}$ \\
medium interaction & 0.003 & 2 & 0.001 & 1.2 & 0.321 \\
\hline
\end{tabular}

df: degrees of freedom $=(n-1), *$ : Significant at $P \leq 0.05$
TABLE (6) Descriptive statistics of surface roughness (Ra) values in $\mu \mathrm{m}$

\begin{tabular}{|c|c|c|c|c|c|c|c|}
\hline \multirow{2}{*}{ 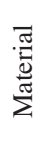 } & \multirow{2}{*}{$\begin{array}{l}\text { Storage } \\
\text { medium }\end{array}$} & \multirow[b]{2}{*}{ Mean } & \multirow[b]{2}{*}{ SD } & \multirow[b]{2}{*}{ Minimum } & \multirow[b]{2}{*}{ Maximum } & \multicolumn{2}{|c|}{$95 \%$ CI } \\
\hline & & & & & & $\begin{array}{l}\text { Lower } \\
\text { bound }\end{array}$ & $\begin{array}{l}\text { Upper } \\
\text { bound }\end{array}$ \\
\hline \multirow{3}{*}{ 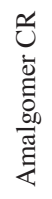 } & $\begin{array}{l}\text { Distilled } \\
\text { water }\end{array}$ & 0.17 & 0.03 & 0.13 & 0.21 & 0.14 & 0.20 \\
\hline & Citric acid & 0.23 & 0.04 & 0.17 & 0.29 & 0.18 & 0.27 \\
\hline & Ethanol & 0.30 & 0.05 & 0.22 & 0.36 & 0.25 & 0.35 \\
\hline \multirow{3}{*}{ 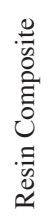 } & $\begin{array}{l}\text { Distilled } \\
\text { water }\end{array}$ & 0.06 & 0.02 & 0.04 & 0.10 & 0.04 & 0.09 \\
\hline & Citric acid & 0.10 & 0.02 & 0.08 & 0.13 & 0.08 & 0.11 \\
\hline & Ethanol & 0.15 & 0.02 & 0.12 & 0.18 & 0.13 & 0.17 \\
\hline
\end{tabular}

Table (7) showed that Amalgomer CR showed significantly higher mean surface roughness $(\mathrm{Ra})$ compared to resin composite in different storage media. For Amalgomer CR, ethanol showed the highest mean $\mathrm{Ra}$ value followed by citric acid then distilled water with statistically significant differences between them. In resin composite, ethanol showed the highest mean $\mathrm{Ra}$ while no statistically significant difference was recorded between citric acid and distilled water.

TABLE (7) Mean, standard deviation (SD) values and p-value of the effect of material and storage media on surface roughness $(\mathrm{Ra})$ in $\mu \mathrm{m}$

\begin{tabular}{lccccc}
\hline \multirow{2}{*}{$\begin{array}{c}\text { Storage } \\
\text { medium }\end{array}$} & \multicolumn{2}{c}{ Amalgomer CR } & \multicolumn{2}{c}{$\begin{array}{c}\text { Resin } \\
\text { composite }\end{array}$} & \multirow{2}{*}{$P$-value } \\
\cline { 2 - 5 } & Mean & $\mathrm{SD}$ & Mean & $\mathrm{SD}$ & \\
\hline Distilled water & $0.17^{\mathrm{C}}$ & 0.03 & $0.06^{\mathrm{C}}$ & 0.02 & $<0.001^{*}$ \\
Citric acid & $0.23^{\mathrm{B}}$ & 0.04 & $0.10^{\mathrm{BC}}$ & 0.02 & $<0.001^{*}$ \\
Ethanol & $0.30^{\mathrm{A}}$ & 0.05 & $0.15^{\mathrm{A}}$ & 0.02 & $<0.001^{*}$ \\
$P$-value & $<0.001^{*}$ & \multicolumn{2}{c}{$<0.001^{*}$} & \\
\hline
\end{tabular}

*: Significant at $P \leq 0.05$, Different superscripts in the same column are statistically significantly different 


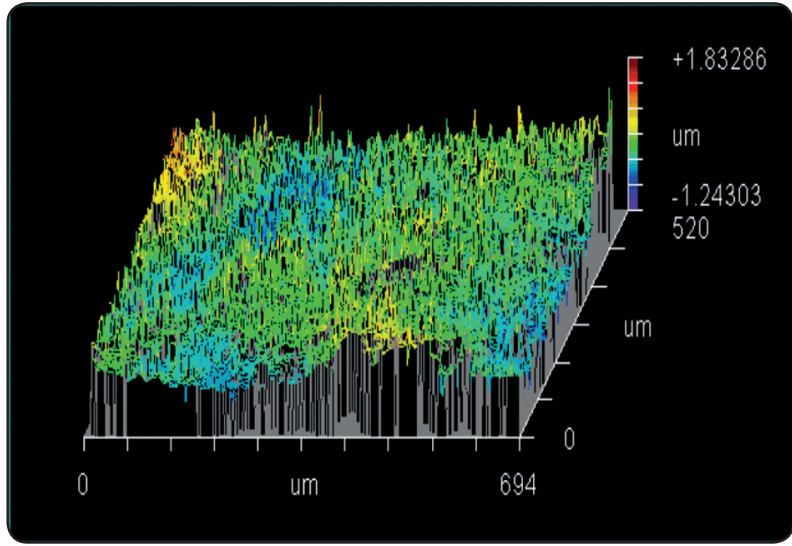

Fig. (1a) Interferometer image of the Amalgomer CR after storage in distilled $\mathrm{H} 2 \mathrm{O}$

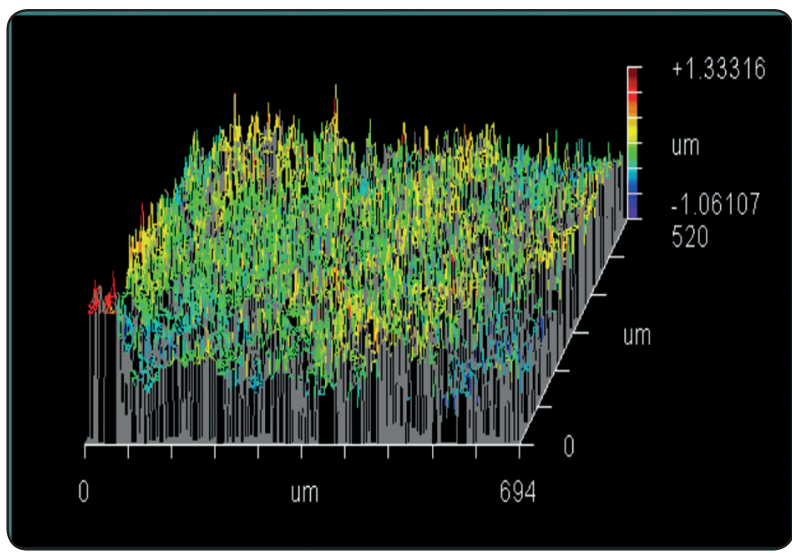

Fig. (1c) Interferometer image of the Amalgomer CR after storage in citric acid

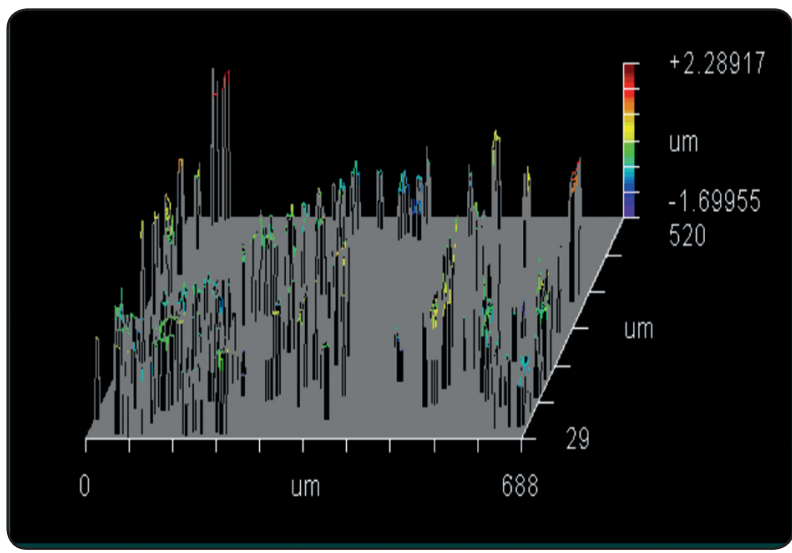

Fig. (1e) Interferometer image of the Amalgomer CR after storage in ethanol

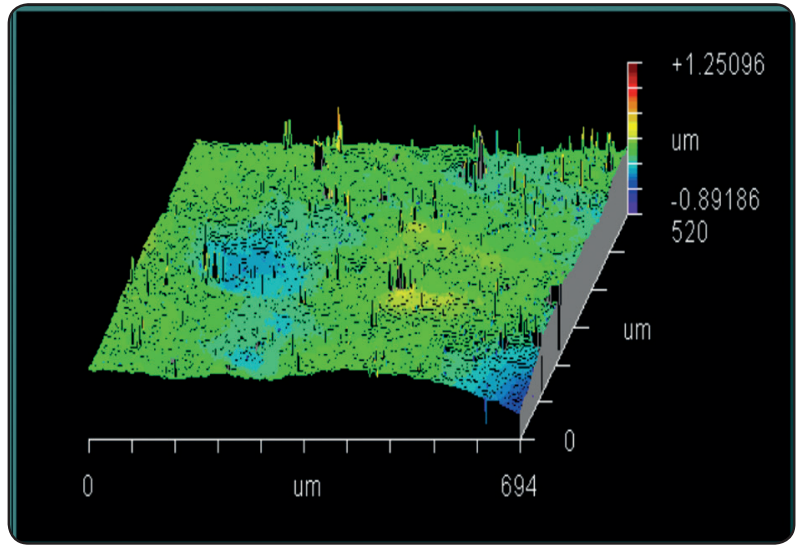

Fig. (1b) Interferometer image of the resin composite after storage in distilled $\mathrm{H} 2 \mathrm{O}$

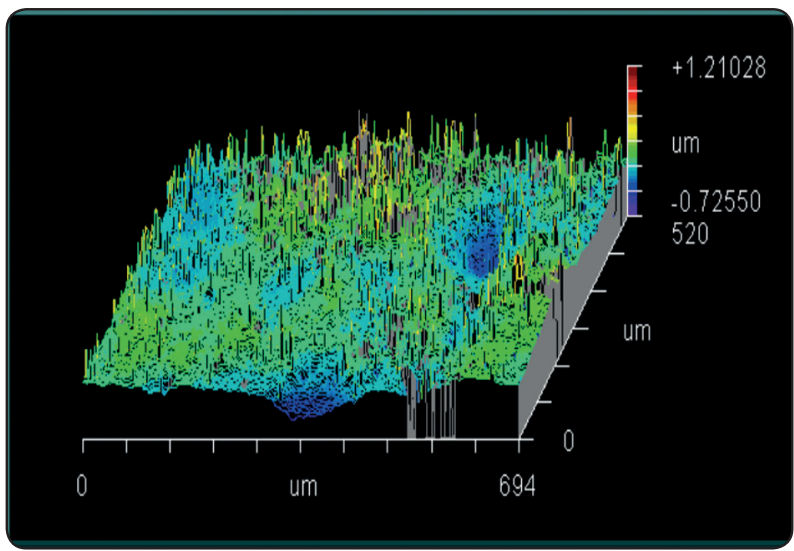

Fig. (1d) Interferometer image of the resin composite after storage in citric acid

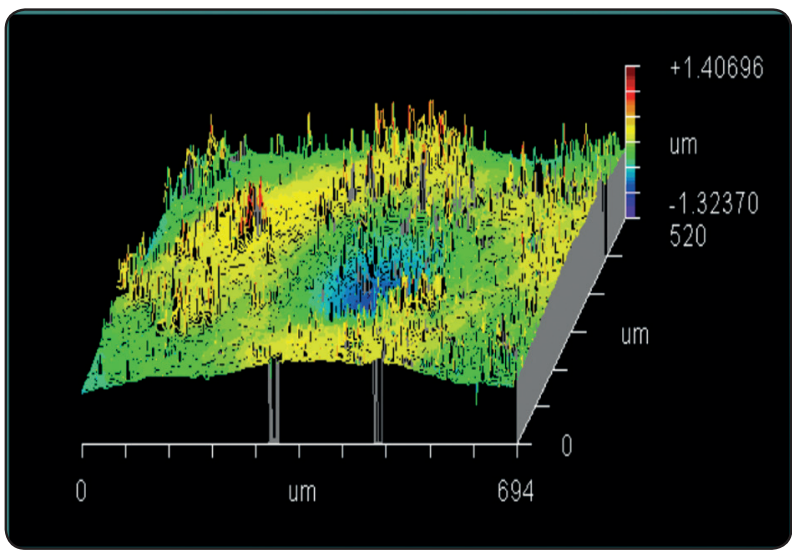

Fig. (1f) Interferometer image of the resin composite after storage in ethanol

Fig. 1 (a-f): Interferometer images of Amalgomer CR and nanofilled resin composite after immersion in different storage media 


\section{Scanning Electron Microscopic Observations}

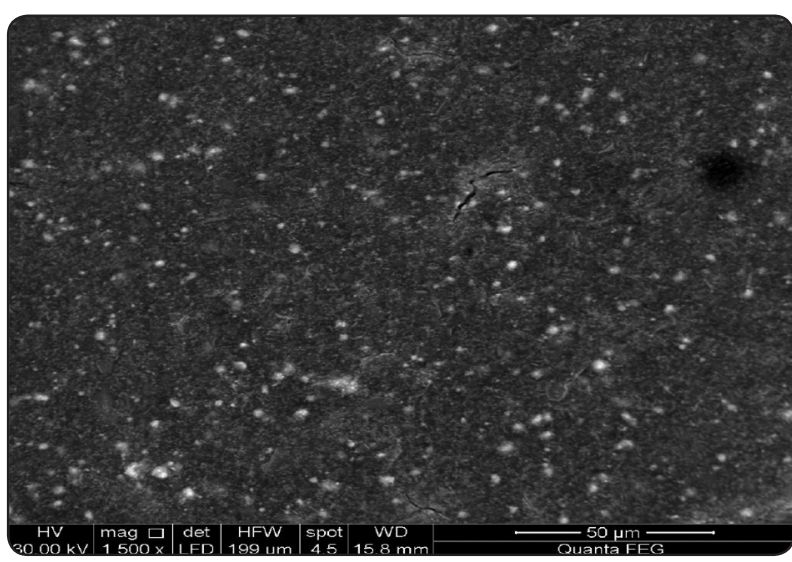

Fig. (2a) SEM image of the Amalgomer CR after storage in distilled $\mathrm{H} 2 \mathrm{O}$

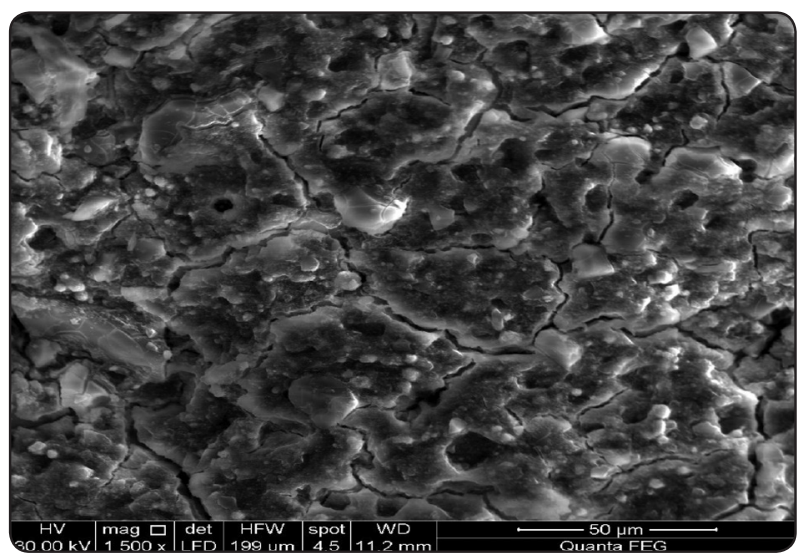

Fig. (2c) SEM image of the Amalgomer CR after storage in citric acid

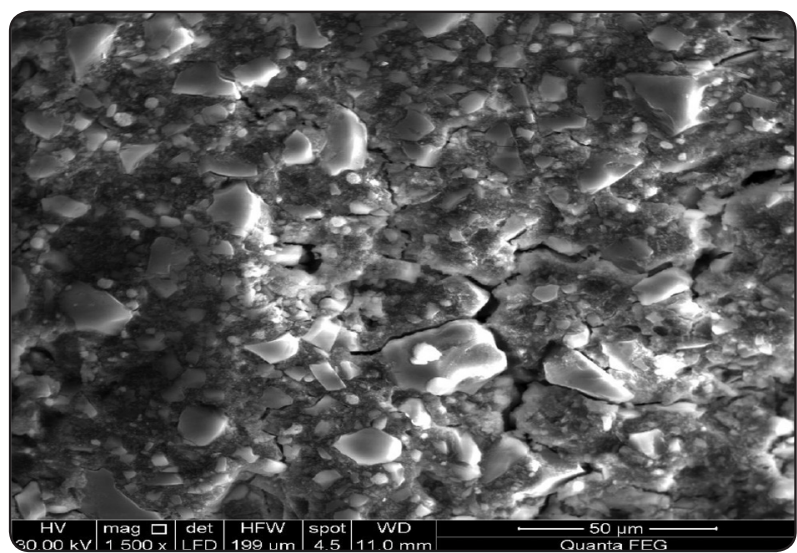

Fig. (2e) SEM image of the Amalgomer CR after storage in ethanol

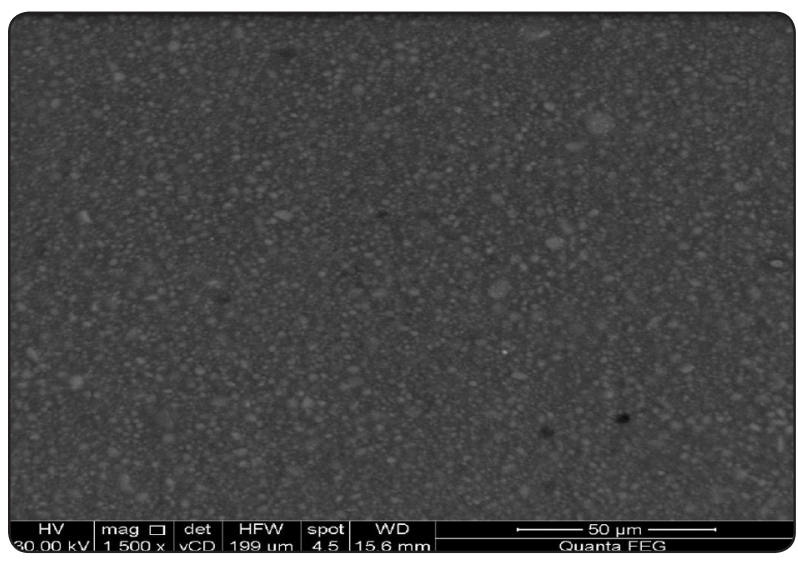

Fig. 2b: SEM image of the resin composite after storage in distilled $\mathrm{H} 2 \mathrm{O}$

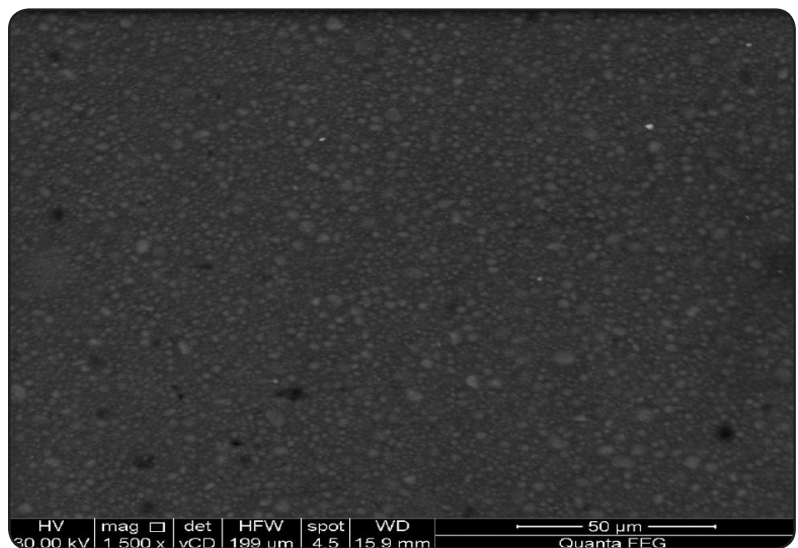

Fig. (2d) SEM image of the resin composite after storage in citric acid

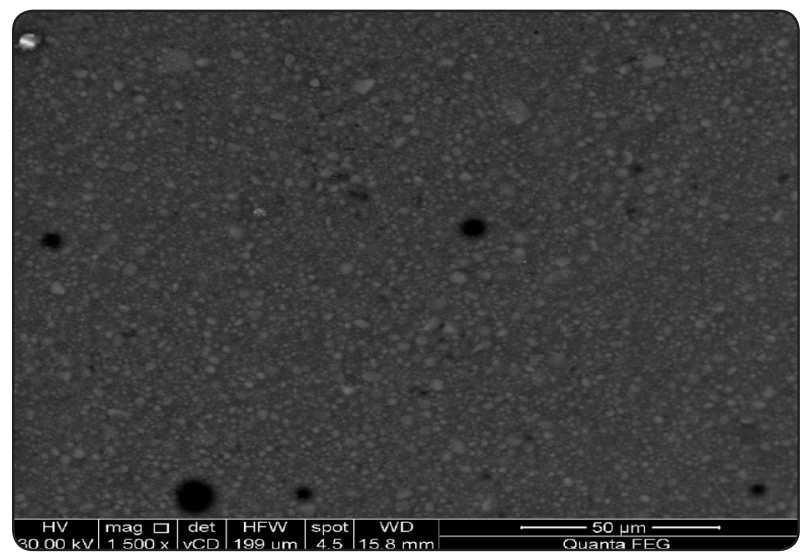

Fig. (2f) SEM image of the resin composite after storage in ethanol

Figure 2 (a-f): SEM images of Amalgomer CR and nanofilled resin composite after immersion in different storage media 
Scanning electron microscopic images showed that Amalgomer CR specimens immersed in distilled water (fig 2a) revealed a uniform surface layer while those immersed in citric acid (fig 2c) showed surface alterations due to matrix degradation with observed cracks, irregularities and empty spaces probably due to detached fillers. Specimens stored in ethanol (fig 2e) showed irregular surface with multiple cracks and prominent fillers of different sizes. Regarding resin composite, SEM images showed uniform surface in the specimens immersed in distilled water (fig 2b). Specimens immersed in citric acid (fig $2 \mathrm{~d}$ ) revealed slight alteration in surface topography due to filler dislodgement in some areas. Such topographical feature was more pronounced with larger concavities in specimens stored in ethanol (fig 2f).

\section{DISCUSSION}

The current study was conducted to evaluate the compressive strength and surface roughness of ceramic reinforced glass ionomer after immersion in distilled water, citric acid and ethanol in comparison to a nanofilled resin composite.

Chemical challenges are one of the most important degrading factors of the oral environment which could be in a continuous or intermittent mode. In case of poor oral hygiene patients or inaccessible areas in the oral cavity, chemicals could be absorbed by remaining food debris or accumulated plaque on restorations' margins. This acts as a continuous reservoir for such chemicals. On the other hand, eating or drinking of chemicals represents the intermittent exposure ${ }^{16,17}$.

The US Food and Drug Administration recommended some food simulating fluids to be used during testing of materials' aging which were followed in the current study. Distilled water simulates the wet oral environment provided by the presence of saliva and water. Consumption of acidic foods such as certain beverages, fruits and vegetables was represented by citric acid solution. Aqueous ethanol water solution simulates alcoholic liquids ${ }^{18}$.

In the present study, no finishing and polishing procedures were done to provide standardization and avoid surface modifications of the specimens ${ }^{19}$. The specimens were immersed in the recommended solutions for 7 days at $37^{\circ} \mathrm{C}$. This period of immersion was chosen to accelerate the effect of the food simulating liquids in accordance with previous methods described in the literatures ${ }^{13,15,16}$.

In the current study, Amalgomer CR recorded lower compressive strength in comparison to nanofilled composite under different storage media. The manufacturer of Amalgomer CR did not report any information about the filler size and filler percentage of its zirconia fillers. However, it seems that the mechanical performance of the used nanofilled resin composite relays on the fact that it uses nanoscaled filler particles which allows higher filler loading ${ }^{10}$. The difference in filler size and distribution between Amalgomer CR and nanofilled composite could be observed in the SEM images especially in specimens stored in citric acid and ethanol (figure 2). This was in accordance with Souza et al, $2016^{11}$ who found that nanohybrid composite has higher compressive strength than zirconia and alumina reinforced glass ionomer cement.

The inferior performance of Amalgomer CR might be attributed to its moisture sensitivity, being a water based material that consists of ionleachable glass and water soluble polymeric acids ${ }^{20}$. A previous study ${ }^{20}$ found that Amalgomer CR recorded higher water sorption value than resin composite. This might in turn affect its mechanical strength properties.

The weak bond between zirconia fillers and glass ionomer matrix might be another explanation for the lower compressive strength of Amalgomer CR. Yli-Urpo et al, $2005^{5}$, reported a massive 
reduction in compressive strength of glass ionomer after addition of bioactive glass and attributed this finding to the loose attachment of these particles to glass ionomer matrix.

Immersion of Amalgomer CR in citric acid recorded a major drop in its compressive strength. This might be attributed to the severe dissolution and degradation of GIC by citric acid as described by Kumar et al, 2014 \& Maganur et al, $2015^{21,22}$ They demonstrated that hydrogen ions of citric acid diffused into the glass ionomer components and replace metal cations in the matrix in a continuous process causing progressive dissolution of the GIC. Kooi et al, 2012 ${ }^{15}$, reported a significant degradation of giomer by citric acid and attributed this to the great susceptibility of fluorosilicate glass fillers to degradation by weak acids. Another research ${ }^{23}$ demonstrated severe erosion of GIC by citric acid with considerable bulk loss of the material. This was also revealed in the current study where an obvious reduction in the specimens' size has been observed. This bulk loss of the material could explain the diminished mechanical properties.

Compressive strength of nanofilled resin composite recorded a significant decrease after immersion in ethanol and citric acid in comparison to distilled water. Ethanol is characterized by having a solubility parameter matching with that of BisGMA ${ }^{15}$. It also has high ability to extract unreacted monomers as it can penetrate through the resin matrix causing swelling of the polymeric chains $^{24,25}$ and degradation of filler-matrix interface ${ }^{26}$ which consequently reduces it mechanical properties. Citric acid could affect resin composite by causing ionic dissolution of filler particles ${ }^{14}$.

Regarding surface roughness results, Amalgomer $\mathrm{CR}$ recorded a significantly higher surface roughness than nanocomposite with different immersion solutions. Surface roughness is greatly influenced by size of filler particles and percentage of fillers occupying the restoration surface ${ }^{27}$. De Paula et al,
$2015^{28}$, reported that there is a direct relationship between size of filler particles and material loss. This result was in accordance with Kantovitz et al, $2009^{14}$, who reported higher surface roughness of ionomer materials in relation to resin sealant materials under acidic conditions. They attributed this result to fluoride release of glass ionomer cements. Also, Hamouda, $2011^{29}$, reported the same finding and explained it by the larger particle size and moisture sensitivity of GIC.

Although, surface roughness of nanofilled resin composite significantly increased after immersion in citric acid and ethanol, it remains within the threshold of surface roughness for bacterial retention which is $0.2 \mu \mathrm{m}{ }^{21}$. This might be due to the high filler percentage and the nano-sized filler particles with minimal inter-particle spacing ${ }^{8}$. The good bonding of fillers to the resin matrix due the presence of silane coupling agent might be another explanation ${ }^{29}$. In addition, exfoliation of fillers from the restoration surface results in formation of very small surface defects ${ }^{28}$.

Despite the aggressiveness of citric acid which results in massive reduction in compressive strength especially with GIC, it recorded lower surface roughness values than ethanol for both materials (table 7). This high aggressiveness might result in softening of resin matrix ${ }^{13}$ in association with the ionic dissolution and loss of filler particles ${ }^{14}$ which probably leads to the removal of a uniform layer of the material with bulk loss. However, ethanol results in matrix degradation without loss of filler particles. SEM images of Amalgomer CR after immersion in ethanol (fig 2c) shows the presence of prominent filler particles of various sizes which might justify their higher surface roughness values.

Based on the results obtained in the present study, the addition of ceramic fillers to glass ionomer cement did not improve the material performance in comparison to nanofilled resin composite. Ceramic reinforced glass ionomer cements still have 
limitations regarding their resistance to chemical degradation as revealed in the compressive strength and surface roughness results. Nevertheless, further investigations are recommended to improve the performance of glass ionomer cements under different chemical environmental conditions.

\section{CONCLUSIONS}

Despite of the limitations of the current study, the following could be concluded:

1- The performance of Amalgomer CR under different storage media was inferior to nanofilled resin composite regarding compressive strength and surface roughness.

2- Citric acid severely affected compressive strength of Amalgomer CR.

3- Nanofilled resin composite was able to preserve its surface roughness within the clinically acceptable threshold after chemical challenge in contrary to Amalgomer CR.

\section{REFERENCES}

1. Sayyedan FS, Fathi MH, Edris H, Doostmohammadi A, Mortazavi V, Hanifi A. Effect of forsterite nanoparticles on mechanical properties of glass ionomer cements. Ceram Int 2014; 40(7):10743-10748.

2. Khaghani M, Alizadeh S, Doostmohammadi A. Influence of incorporating fluoroapatite nanobioceramic on the compressive strength and bioactivity of glass ionomer cement. J Dent Biomater 2016; 3(3):276-283.

3. Xie D, Brantley WA, Culbertson BM, Wang G. Mechanical properties and microstructures of glass-ionomer cements. Dent Mater 2000; 16(2):129-138.

4. Griffin SG, Hill RG. Influence of glass composition on the properties of glass polyalkenoate cements. Part I: influence of aluminium to silicon ratio. Biomaterials 1999; 20(17):1579-1586

5. Yli-Urpo H, Lassila LVJ, Närhi T, Vallittu PK. Compressive strength and surface characterization of glass ionomer cements modified by particles of bioactive glass. Dent Mater $2005 ; 21: 201-209$.
6. Lyapina MG, Tzekova M, Dencheva M, Krasteva A, Yaneva-Deliverska M, Kisselova A. Nano-glass-ionomer cements in modern restorative dentistry. J IMAB 2016; 22(2):1160-1165.

7. Advanced Healthcare Limited K. Amalgomer CR Technology. Advanced Dental Restoratives. In: Advanced Healthcare Limited KTJ, ed. 2004. Accessed 8th Angust; 2012. Available:WWW.AMALGOMER.COM

8. Sachdeva S, Kapoor P, Tamrakar AK, Noor R. Nano-composite dental resins: an Overview. Annals of Dental Specialty $2015 ; 3(2): 52-55$.

9. Hegde MN, Hegde P, Bhandary S, Deepika K. An evalution of compressive strength of newer nanocomposite: An in vitro study. J Conserv Dent 2011; 14(1);36-39.

10. Kiran KV, Tatikonda A, Jhajharia K, Raina S , Lau H, Katare D, Kaur RK. In vitro evaluation of compressive strength of microhybrid and nanocomposite. Oral Health Dent Manag 2014; 13(4):1171- 1173

11. Souza JCM, Silva JB, Aladim A, Carvalho O, Nascimento RM, Silva FS, Martinelli AE, Henriques B. Effect of zirconia and alumina fillers on the microstructure and mechanical strength of dental glass ionomer cements. The Open Dent J 2016; 10:58-68.

12. Da Silva MAB, Vitti RP, Sinhoreti MAC, Consani RLX, da Silva-Junior JG, Tonholo J. Effect of alcoholic beverages on surface roughness and microhardness of dental composites. Dent Mater J 2016; 35(4):621-929.

13. Voltarelli FR, dos Santos-Daroz CB, Alves MC, Cavalcanti AN, Marchi GM. Effect of chemical degradation followed by toothbrushing on the surface roughness of restorative composites. J Appl Oral Sci 2010; 18(6):585-590.

14. Kantovitz KR, Pascon FM, Correr GM, Alonso RCB, Rodrigues LKA, Alves MC, Puppin-Rontani RM. Influence of environmental conditions on properties of ionomeric and resin sealant materials. J Appl Oral Sci 2009; 17(4):294-300

15. Kooi TJM, Tan QZ, Yap AUJ, Guo W, Tay KJ, Soh MS Effects of food-simulating liquids on surface properties of giomer restoratives. Oper Dent 2012; 37(6):665-671.

16. Akova T, Ozkomur A, Uysal H. Effect of food simulating liquids on the mechanical properties of provisional restorative materials. Dent Mater 2006; 22:1130-1134.

17. Yap AU, Tan SH, Wee SS, Lee CW, Lim EL, Zeng KY. Chemical degradation of composite restoratives. J Oral Rehabil 2001; 28: 1015-1021. 
18. Food and Drug Administration, Bureau of Foods (1976) Guidelines for Chemistry and Technology Department of Health, Education and Welfare, Washington, DC 11.

19. Rocha ACC, Lima CSA, Santos MDM, Montes MAJR. Evaluation of surface roughness of a nanofill resin composite after simulated brushing and immersion in mouthrinses, alcohol and water. Mater Res 2010; 13(1):77-80

20. Bamise CT, Mejabi MO, Esan TA. Short term sorption effect on three esthetic dental filling materials in various media. Advances in Research 2015; 5(6):1-9.

21. Kumar RA, Venkatesan SM, Narayan GS, Duraivel D, Indra R. Influence of citric acid on the surface texture of glass ionomer restorative materials. J Conserv Dent 2014; 17(5):436-439.

22. Maganur P, Satish V, Prabhakar AR, Namineni S. Effect of soft drinks and fresh fruit juice on surface roughness of commonly used restorative materials. Inter J Clin Pediatr Dent 2015; 8(1):1-5.

23. Wan Bakar WZ, McIntyre J. Susceptibility of selected tooth-coloured dental materials to damage by common erosive acids. Aust Dent J 2008; 53:226-234.
24. Hegde MN, Bhat GT, Nagesh SC. Release of monomers from dental composite materials-An invitro study. Int $\mathrm{J}$ Pharm Pharm Sci 2012; 4(3):500-504.

25. Tabatabaei TMH, Sadrai S, Bassir SH, Veisy N, Dehghan S. Effect of food stimulated liquids and thermocycling on the monomer elution from a nanofilled composite. The Open Dent J 2013; 7:62-67.

26. Yesilyurt C, Yoldas O, Altintas SH, Husgoz A. Effects of food-simulating liquids on the mechanical properties of a silorane based dental composites. Dent Mater J 2009; 28(3):362-367.

27. Marghalani HY. Effect of filler particles on surface roughness of experimental composite series. J Appl Oral Sci 2010; 18(1):59-67.

28. De Paula AB, Alonso RCB, De Araújo GAS, Rontani JP, Correr-Sobrinho L, Puppin-Rontani RM. Influence of chemical degradation and abrasion on surface properties of nanorestorative materials. Braz J Oral Sci 2015;14 (2): 100-105.

29. Hamouda IM. Effects of various beverages on hardness, roughness and solubility of esthetic restorative materials. J Esth Rest Dent 2011; 23(5):315-322. 